\title{
The great 1950 Assam Earthquake revisited: field evidences of liquefaction and search for paleoseismic events
}

\author{
DV Reddy ${ }^{1}$, Pasupuleti Nagabhushanam¹, Devender Kumar ${ }^{1 *}$, Balbir S Sukhija ${ }^{1}$, PJ Thomas ${ }^{1}$, Anand \\ K Pandey ${ }^{1}$, Radhendra Nath Sahoo ${ }^{1,2}$, GV Ravi Prasad ${ }^{3}$ and Koushik Datta ${ }^{3}$ \\ 1 National Geophysical Research Institute, Uppal Road, Hyderabad - 500 606, INDIA \\ 2 Present Address: Kishan Ganga Hydro Electric Project, National Hydroelectric Power Corporation, PDD Colony, Ghantamulla -193 101, INDIA \\ 3 Institute of Physics, Sachivalaya Marg, Bhubaneshwar-751 005, INDIA \\ * For correspondence, email: devngri@gmail.com
}

Extensive field investigations were carried out for the first time in the meizoseismal area of the Great 1950 Assam earthquake aimed at exploring the paleoseismic history of NE Indian region through documentation of liquefaction features. The precondition for any liquefaction like the presence of shallow water table, unconsolidated sand and shear wave as triggering agent prevail at the studied sites in the Brahmaputra valley. In such potential seismic zone a large number of liquefaction sites were expected to exist. Contrary to this, our extensive field investigations in this meizoseismal area could unravel only a few sites with liquefaction features. Non-availability of liquefaction sites within the flood plains of Brahmaputra River could be attributed to either sediment erosion or deep burial during seasonal floods. However, the sites located inland or close to low energy flood environment are quite suitable for preservation of liquefaction features. Owing to this, we could locate the liquefaction features mainly along and adjoining areas of Burhi Dihing river, a major tributary of Brahmaputra, and a few locations in distal part of the alluvial fans. The liquefaction features, like sand blows, dykes and sills, crater, and associated soft sediment deformation features were observed in trenches at different depths from the ground surface. The liquefaction sites namely Haldibari, Khowang, Sapakhoaghat, Zinimari, Nagaon, Kalolwa, and Borbaligaon are distributed in lower reaches of Burhi Dihing River, while Jiya Nala, and Kaliya Nala fall in the distal part of alluvial fans of Dibang River near Sadiya. In order to constrain the formation timing of the different liquefaction features and causative earthquakes, associated organic material samples (e.g. charcoal, wood, peat) were collected. Out of 12 features, one feature at Haldibari site dates Modern $(\leq 50$ yr) for its lower, upper and penecontemporaneous bounds, thus exclusively constraining the 1950 earthquake. For some of the sand dykes, we obtained lower bound ages of about $500 \mathrm{yr}$, which infer the features might have formed any time after $1370 \mathrm{AD}$ (Figure 1 ). We might have documented the signatures of historically reported $1548 \mathrm{AD}$ and $1697 \mathrm{AD}$ seismic events, but were devoid of organic material for $14 \mathrm{C}$ dating. Thus the paleoseismic history dating back to $\sim 500 \mathrm{yr}$ BP documented through $14 \mathrm{C}$ chronology of the organic material associated with these features indicates the absence of a comparable magnitude earthquake of that of 1950 in the studied area.

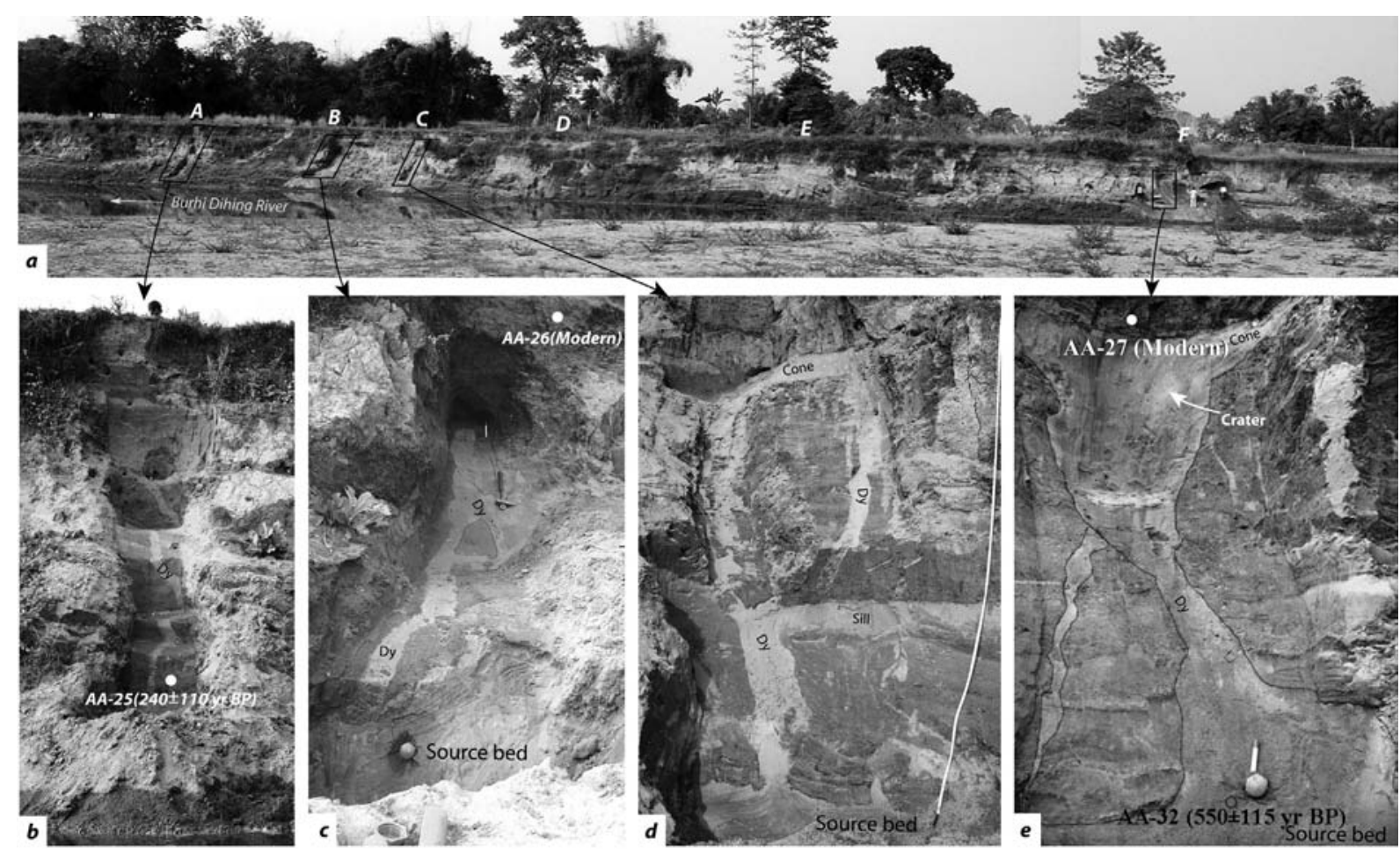

FIGURE 1. A series of dykes exposed in a 140 $m$ long section in NW direction on the right bank of Burhi Dihing River at Nagaon. All the major dykes are numbered as $\mathrm{A}$ to $F$. Blow up of a few individual dykes along with the respective $14 \mathrm{C}$ ages are shown. 